\title{
Surface Initiated Polymerization from Substrates of Low Initiator Density and Its Applications in Biosensors
}

\author{
Hongwei Ma, ${ }^{*}{ }^{\dagger}$ Jian’an He, ${ }^{\mp}$ Xing Liu, ${ }^{\dagger}$ Jianhong Gan, ${ }^{\S}$ Gang Jin," and Jiahai Zhou ${ }^{\perp}$
}

Suzhou Institute of Nano-Tech and Nano-Bionics, Chinese Academy of Sciences, Suzhou 215123, P. R. China, Department of Biomedical Engineering, College of Engineering, Peking University, Beijing 100871, P. R. China, College of Food Science \& Technology, Shanghai Ocean University, Shanghai 201306, P. R. China, Institute of Mechanics, Chinese Academy of Sciences, Beijing 100090, P. R. China, Shanghai Institute of Organic Chemistry, Chinese Academy of Sciences, Shanghai 200032, P. R. China

\begin{abstract}
Surface initiated polymerization (SIP) has become an attractive method for tailoring physical and chemical properties of surfaces for a broad range of applications. Most of those applications relied on the merit of high density coating. In this study, we explored a long overlooked field of SIP: SIP from substrates of low initiator density. We combined ellipsometry with AFM to investigate the effect of initiator density and polymerization time on the morphology of polymer coatings. In addition, we carefully adjusted the nanoscale separation of polymer chains to achieve a balance between nonfouling and immobilization capacities. We further tested the performance of those coatings on various biosensors, such as quartz crystal microbalance, surface plasmon resonance, and protein microarrays. The optimized matrices enhanced the performance of those biosensors. This report shall encourage researchers to explore new frontiers in SIP that go beyond polymer brushes.
\end{abstract}

KEYWORDS: surface initiated polymerization $\bullet$ biosensor matrix $\bullet$ quartz crystal microbalance $\bullet$ surface plasmon resonance $\bullet$ protein microarray

S urface initiated polymerization (SIP) was initially designed to overcome the concentration barrier problem commonly suffered in the "grafting to" strategy, so that higher grafting density (>0.06 chain $\mathrm{nm}^{-2}$ ) (1) could be achieved. As a "grafting from" strategy, SIP grew polymers from the surface tethered initiators, which could be immobilized to surfaces with high density via well-established techniques such as that of self-assembled monolayer (SAM) $(2,3)$. SIP has been used to tailor physical and chemical properties of surfaces for a broad range of substrates and applications. Substrates include inorganic (4-9), polymer (10-13), metal (14-17), semiconductor (18), ceramic (19), and biological materials (20-22). Applications include nonfouling (23-27), wettability (28-31), responsive surfaces (32-35), corrorison resistance (36), lithographic coating (37), colloid stability (5), and stealth effect $(22,38)$. Most of those applications relied on the merit of higher density coating achieved by SIP. However, we found that only SIP from a low, not high, initiator density could produce superhydrophobic surfaces (39). This finding reminded us that

\footnotetext{
* To whom correspondence should be addressed. E-mail: hwma2008@ sinano.ac.cn.

Received for review August 3, 2010 and accepted September 30, 2010

† Suzhou Institute of Nano-Tech and Nano-Bionics, Chinese Academy of Sciences.

* Peking University

$\S$ Shanghai Ocean University.

"Institute of Mechanics, Chinese Academy of Sciences.

${ }^{\perp}$ Shanghai Institute of Organic Chemistry, Chinese Academy of Sciences.

DOI: $10.1021 /$ am 1006832

2010 American Chemical Society
}

SIP not only produced high density brushes but also allowed us to precisely control many aspects of the resulting polymers, such as film thickness and density, composition (i.e., block copolymers), and functionality. Inspired by this finding, we decided to explore a long overlooked field of SIP: SIP from substrates of low initiator density. Specificially, we applied SIP from substrates of low initiator density to prepare biosensor matrices.

The design and preparation of biosensor matrices have attracted a great deal of interest because the performance of biosensors is greatly affected by the characteristics of matrices, such as their chemical composition, three-dimensional (3D) structures, mechanical properties, and biocompatibility. For example, Liedberg et al. developed a poly(ethylene glycol) matrix via UV-initiated free radical polymerization (40). Gopalan et al. prepared poly(acrylic acid) (PAA) brushes via atom transfer radical polymerization (ATRP) to immobilize ribonuclease A (41). Although polymer density has been studied as a potential factor that alters matrix performance (42-46), few reports systematically assessed the effect of density on the performance of the biosensor, especially for initiator densities below $5 \%$. Herein, we combined ellipsometry with atomic force microscopy (AFM) to investigate the effect of initiator density and polymerization time on the morphology of polymer coatings prepared by SIP from substrates of low initiator density. We further tested the performance of those coatings on various biosensors, such as quartz crystal microbalance (QCM), surface plasmon resonance (SPR), and protein microarrays. Our 
results, that the optimized matrices enhanced the performance of biosensors, were encouraging.

\section{EXPERIMENTAL SECTION}

Materials and Methods. The initiator thiol $(\omega$-mercaptoundecyl bromoisobutyrate), 11 -(mercaptoundecyl)tri(ethylene glycol) (EG3-thiol), SPR, and QCM chips were purchased from HRBio (Beijing, China). Oligo(ethylene glycol) methacrylate (OEGMA), 2-hydroxyethyl methacrylate (HEMA), anhydrous $\mathrm{N}, \mathrm{N}^{\prime}$-dimethylformamide (DMF), succinic anhydride, and 4-(dimethylamino)pyridine (DMAP) were purchased from Aldrich. $\mathrm{N}$-ethyl- $\mathrm{N}^{\prime}$-[3-dimethylaminopropy]carbodiimide hydrochloride (EDC) and hydroxy-2,5-dioxopyrolidine-3-sulfonicacid sodium salt (NHSS) were purchased from Medpep (Shanghai, China). Glycine (Gly) was purchased from Dingguo (Beijing, China). Goat anti-rabbit IgG, rabbit IgG, and bovine serum albumin were purchased from Bioss (Beijing, China).

Preparation of Poly(OEGMA-co-HEMA). The mixed SAMs of initiators $\omega$-mercaptoundecyl bromoisobutyrate and EG3-thiol were prepared by immersing the Au-coated QCM or SPR chips into a $1 \mathrm{mM}$ mixed solution (total concentration) of two thiols with a desired ratio for $15 \mathrm{~h}$ at room temperature. The chips modified with mixed SAMs were thoroughly rinsed with ethanol three times to remove the physisorbed initiator and then dried in a stream of nitrogen. The poly(OEGMA-co-HEMA) matrices were prepared in the same manner for both QCM and SPR chips. The reaction solution was prepared by mixing it well with Milli-Q-water ( $5 \mathrm{~mL})$, methanol ( $5 \mathrm{~mL})$, bipyridine ( $\sim 12.5 \mathrm{mg}$, $0.8 \mathrm{mmol})$, and monomers OEGMA526 (2.65 g, $5 \mathrm{mM})$ and HEMA $(0.65 \mathrm{~g}, 5 \mathrm{mM})$. We added a further $1 \mathrm{~mL}$ of $\mathrm{CuCl}_{2}(0.04$ $\mathrm{mM}$ ) to the mixed solution. After the transparent, pale-blue solutions were deoxygenated for $15 \mathrm{~min}, 1 \mathrm{~mL}$ of ascorbic acid (AscA; $0.04 \mathrm{mM}$ ) was injected with a syringe. The mixture was further deoxygenated and the resulting mixture was red in color due to the reduction of the deactivator $\mathrm{Cu}(\mathrm{II}) / \mathrm{Bipy}$ complex to the activator $\mathrm{Cu}(\mathrm{I}) / \mathrm{Bipy}$ complex. This mixture was then transferred to a reaction setup in an inert gas glove box, and SIP was initiated and continued for a specified time at room temperature. The polymerization was stopped when chips were removed from the solution. Samples were thoroughly rinsed with methanol and Milli-Q-water and dried under flowing nitrogen. EG3-thiol SAMs were prepared by immersing the QCM and SPR chips into a $1 \mathrm{mM}$ EG3-thiol solution for $15 \mathrm{~h}$ at room temperature. The chips were incubated into a DMF solution containing succinic anhydride $\left(10 \mathrm{mg} \mathrm{mL}^{-1}\right)$ and DMAP $\left(15 \mathrm{mg} \mathrm{mL}^{-1}\right)$ for $12 \mathrm{~h}$ for carboxylation.

Characterization Methods. Ellipsometry. Film thickness was measured on a M-2000 V spectroscopic ellipsometer (J. A. Woollam Co., Inc.) at angles of $65^{\circ}, 70^{\circ}$, and $75^{\circ}$ and wavelengths from 400 to $800 \mathrm{~nm}$. Ellipsometric data were fitted for the thickness with material specific models, i.e., SAMs and poly(OEGMA-co-HEMA) matrixes with fixed (An, Bn) values of $(1.45,0.01)$ and $(1.46,0.01)$, respectively, using a cauchy layer model. The ellipsometric thickness for each sample was independently measured at three different locations and was reported as the average \pm standard error. AFM images of samples in their dry state were taken in the tapping mode (Digital Instruments, Santa Barbara).

Applications. QCM. QCM experiments were performed on a home-built instrument with control software purchased from Resonant Probes GmbH (Goslar, Germany). For a QCM chip coated with a carboxylated poly(OEGMA-co-HMEA) matrix, it was first probed by the running buffer, followed by NHSS/EDC activation. Then, rabbit IgG $\left(50.0 \mu \mathrm{g} \mathrm{mL} \mathrm{m}^{-1}\right)$ in a HAc buffer $(2$ $\mathrm{mM}, \mathrm{pH}=4.6$ ) was introduced. Ethanol amine (EtAmine at 1 $\mathrm{M}, \mathrm{pH}=8.5$ ) was applied to deactivate the remaining active carboxyl groups. The running buffer was then switched to phosphate buffered saline (PBS; $\mathrm{pH}=7.4$ ), followed by flowing through goat anti-rabbit IgG (50 $\left.\mu \mathrm{g} \mathrm{mL}^{-1}\right)$, and then switched back to PBS to established a stable baseline.

$S P R$. SPR measurements were performed with a BIAcore 3000 to investigate the performances of the poly(OEGMA-coHEMA) matrices. The temperature was set to $25^{\circ} \mathrm{C}$ and using PBS ( $\mathrm{pH}=7.4)$ as the running buffer. The carboxyl groups were activated by a 5 min injection of an aqueous mixture of NHSS $(0.2 \mathrm{M})$ and $\mathrm{EDC}(0.1 \mathrm{M}$; NE). Then, $50 \mu \mathrm{L}$ of rabbit IgG at 50.0 $\mu \mathrm{g} \mathrm{mL}^{-1}$ diluted with HAc buffer $(2 \mathrm{mM}, \mathrm{pH}=4.6)$ was introduced over the activated surface to evaluate the capacity of protein immobilization, followed by the introduction of ethanol amine (EtAmine at $1 \mathrm{M}, \mathrm{pH}=8.5$ ) to deactivate the remaining active carboxyl groups and subsequent antibody recognition by flowing $100 \mu \mathrm{L}$ through goat anti-rabbit IgG (50.0

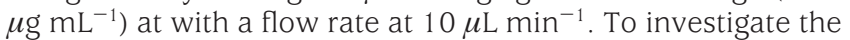
nonfouling property of poly(OEGMA-co-HEMA) matrices, $50 \mu \mathrm{L}$ of rabbit IgG at $50.0 \mu \mathrm{g} \mathrm{mL} \mathrm{m}^{-1}$ was introduced before the carboxyl groups were activated with NE. The procedure for bait immobilization (rabbit IgG at $50.0 \mu \mathrm{g} \mathrm{mL}^{-1}$ ) was the same as for QCM. Goat anti-rabbit IgG in a series of concentrations ((1) $25.0 \mu \mathrm{g} \mathrm{mL} \mathrm{m}^{-1}$; (2) $12.5 \mu \mathrm{g} \mathrm{mL} \mathrm{mL}^{-1}$; (3) $9.0 \mu \mathrm{g} \mathrm{mL}^{-1}$; (4) $6.2 \mu \mathrm{g}$ $\mathrm{mL}^{-1}$; (5) $\left.3.1 \mu \mathrm{g} \mathrm{mL} \mathrm{L}^{-1}\right)$, Gly (100 mM, pH $=2.0$ ), and PBS were introduced in turn.

Protein Microarray. As previously described, the slides were activated by immersing them into an aqueous mixture solution of NHSS/EDC for 30 min before printing. An acetic acid solution ( $2 \mathrm{mM}, \mathrm{pH}=4.6$, Invitrogen) containing $30 \%$ glycerol and $0.01 \%$ triton $\mathrm{X}-100$ was chosen as the printing buffer. Rabbit IgG (100 $\mu \mathrm{g} \mathrm{mL} \mathrm{mL}^{-1}$ ) was diluted with the printing buffer to the desired concentrations and then transferred into a 384well plate. The printing robot SmartArrayerTM-48 was purchased from CapitalBio (Beijing, China). After spotting, the printed slide was incubated in a temperature and humidity chamber with a relative humidity of $70 \%$ for $2 \mathrm{~h}$ and then were immersed into ethanol amine (EtAmine at $1 \mathrm{M}, \mathrm{pH}=8.5$ ) for deactivation ( $\sim 30 \mathrm{~min}$ ) before the assay. A cover grid was used to contain the incubation. The solutions of fluorescently labeled goat anti-rabbit IgG were prepared with PBS in a series of concentrations. Each of the resulting pads was directly incubated with $80 \mu \mathrm{L}$ of the fluorescently labeled anti-IgG on the slide for $2 \mathrm{~h}$. Finally, slides were rinsed three times with PBS with tween 20 (PBST) and three times with PBS and dried in a stream of nitrogen. Dried slides were immediately scanned, imaged, and analyzed with a LuxScanTM-10K/B laser confocal scanner (CapitalBio, Beijing, China). The procedure for immobilization of fluorescently labeled BSA (from 10 to $100 \mu \mathrm{g}$ $\mathrm{mL}^{-1}$ ) was the same as that for the immobilization of IgG. After spotting, the printed slide was incubated in a temperature and humidity chamber with a relative humidity of $70 \%$ for $2 \mathrm{~h}$. Finally, slides were rinsed three times with PBST and three times with PBS and dried in a stream of nitrogen. Dried slides were immediately scanned, imaged, and analyzed with a LuxScanTM-10K/B laser confocal scanner.

\section{RESULTS AND DISCUSSION \\ Effects of Initiator Density and SIP Time on Surface Morphology. A large amount of reaseach has} been carried out that has focused on the effect of density on the kinetics of SIP and the properties of the resulting polymer (47-49). Liu et al. simulated the SIP process and found that the properties of polymer brushes were greatly dependent on the coupling between the initiator density and the initiation efficiency (50). Benetti et al. experimentally illustrated the effect of initiator density on the kinetics, the morphology, and the properties of photopolymerized poly(methacrylic acid) (PMAA) layers (51). In this study, we first utilized binary mixed SAMs to systematically vary the 


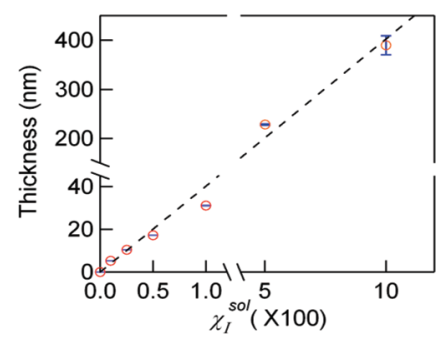

FIGURE 1. A close to linear relation between film thickness and solution ratio of initiator $\left(\chi_{\mathrm{I}}^{\mathrm{Sol}}\right)$. Poly(OEGMA-co-HEMA) was prepared by $8 \mathrm{~h}$ of SIP from substrates of various initiator densities $\left(\chi_{\mathrm{I}}^{\mathrm{Sol}}\right.$ from $0 \%$ to $10 \%$ ); see Experimental Section for details.

surface density of initiators to control the density of polymer chains. EG3-thiol was used to serve two purposes. (i) EG3thiol was used as a diluent to vary initiator (I) density. In this study, we used a solution ratio of initiator $\chi_{1}^{\text {Sol }}\left(\chi_{1}^{\text {Sol }}=n_{1} /\left(n_{1}\right.\right.$ $\left.\left.+n_{\mathrm{EG} 3}\right) \times 100 \%\right)$ to represent the final surface density of the initiator $\left(\chi_{1}^{\text {Sur }}\right)$ because these two are correlated $\left(\chi_{1}^{\text {Sur }} \propto \chi_{1}^{\text {Sol }}\right)$ (52). (ii) EG3-thiol was used as an additional barrier to prevent proteins from nonspecial adsorption to a gold substrate.

Previous studies indicated that the initiator efficiency for SIP from substrates of high initiator density was typically around $10 \%(14,44)$. Thus, we defined $\chi_{1}^{\text {Sol }}<10 \%$ as representing substrates of low initiator density. Furthermore, one could assume that for $\chi_{1}^{\text {Sol }}<10 \%$, each initiator would experience similar polymerization kinetics; thus each initiator would lead to a polymer chain with a similar chain length. From eq 1 , the mass of the resulting polymer film $(\Delta m)$ was proportional to the molecular weight $\left(M_{\mathrm{w}}\right)$ of individual polymer chains and the initiator density:

$$
\begin{gathered}
\Delta m \propto\left(M_{\mathrm{W}}, \chi_{\mathrm{I}}^{\mathrm{sol}}\right) \\
T=\frac{\Delta m}{\rho \cdot S}
\end{gathered}
$$

where $M_{\mathrm{W}}$ and $\chi_{\mathrm{I}}^{\text {sol }}$ are the molecular weight of individual polymer chains and the initiator density (note that we have $\left.\chi_{1}^{\text {Sur }} \propto \chi_{1}^{\text {Sol }}\right)$, respectively, $T$ is the ellipsometric thickness of poly(OEGMA-co-HEMA) at the collapsed state, and $S$ and $\rho$ are the area of polymer coverage and the density of the poly(OEGMA-co-HEMA) matrix, respectively.

At a low initiator density, surface tethered chains have more room to spread laterally so the overall matrix thickness depends on $\chi_{1}^{\text {Sol }}$. Therefore, the thickness of the polymer film at the air-solid interface could be calculated from eq 2 given that $S$ and $\rho$ were known. Here, we further assumed the collapsed polymer film occupied the same surface area and shared the same density. Thus, one would expect a linear relation between measured $T$ and $\chi_{1}^{\text {Sol }}$, which was the case as indicated in Figure 1. To conclude, the initiator density is a critical parameter that determines the surface coverage condition of polymer films (i.e., morphology), which will in turn affect the surface properties or function of surface coatings. More details will be presented below.
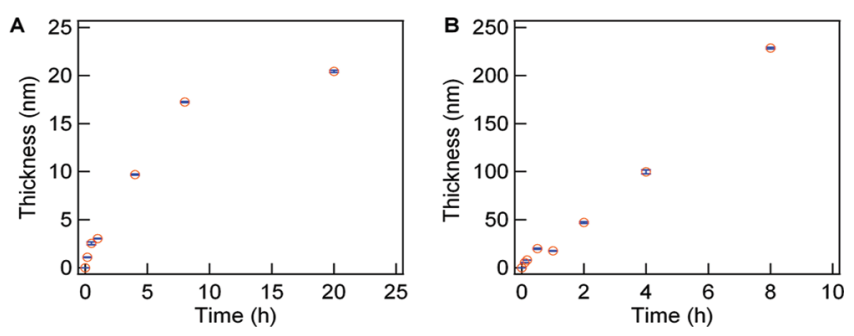

FIGURE 2. Thickness evolution of poly(OEGMA-co-HEMA) coatings as a function of the polymerization time. Two values of $\chi_{1}^{\text {Sol }}$ were tested: (A) $0.5 \%$ and (B) $5 \%$.

Besides the linear relationship between thickness and initiator for coatings prepared from the same SIP time (Figure 1), $T$ increased more or less linearly with the increased polymerization time within the first $8 \mathrm{~h}$ under a fixed $\chi_{1}^{\text {Sol }}$ value, which was demonstrated in Figure 2 with two values of $\chi_{1}^{\text {Sol }}$, namely, $0.5 \%$ and $5 \%$. Since $T$ is a crucial factor in biosensor matrix design, such linear relationships are useful in tuning the thickness of matrices by simply altering the polymerization time. For example, it is very important that proteins diffuse freely into and out of the biosensor matrices in kinetic constants measurement (40). For this purpose, a thin matrix is preferred. However, a thick matrix is desired, so that there will be enough reactive function groups to immobilize ligands for achieving a higher sensitivity.

To study the effect of the initiator density on morphology, the AFM height images and cross-sectional analysis for five $\chi_{1}^{\text {Sol }}$ vlaues are plotted in Figure 3, namely, $0 \%$ (rms $0.9 \mathrm{~nm}$ ), $0.1 \%$ (rms $0.9 \mathrm{~nm}$ ), $0.25 \%$ (rms $0.7 \mathrm{~nm}$ ), $0.5 \%$ (rms 0.6 $\mathrm{nm})$, and $1 \%(\mathrm{rms} 0.7 \mathrm{~nm}$ ) as well as a control bare Au (rms $1.3 \mathrm{~nm}$ ). We observed no significant difference of height images between the bare gold chip and the EG-SAM chip. Both samples showed characteristic valleys and peaks (i.e., the grain structures). The poly(OEGMA-co-HEMA) matrices only reached full coverage on the substrates when the initiator density was above $0.5 \%$, implying that the poly(OEGMA-co-HEMA) matrix grown from a lower initiator density $(<0.5 \%)$ would have difficulties in reducing nonspecific protein adsorption. Therefore, matrices prepared at $\chi_{1}^{\text {Sol }}$ $<0.5 \%$ were not suitable candidates for biosensor applications. We will present detailed results below. Furthermore, for $0 \%<\chi_{1}^{\text {Sol }}<1 \%$, the cross-sectional analysis showed that the average roughness of substrates after SIP decreased as the initiator density increased. We propose a mechanism in Scheme 1 a to explain this roughness $-\chi_{1}^{\text {Sol }}$ relation.

According to Figure 3, we recaptured the surface roughness of the gold surface as $\mathrm{H}$ variations against distance in Scheme $1 \mathrm{a}$. The initiator density was varied from $0 \%$ to $1 \%$. And polymer chains (i.e., the blue lines in Scheme 1a) were added after a fixed SIP time. From the $0.1 \%$ sample in Figure 3, we noticed the number of valleys and peaks decreased as compared with SAM modified chips, which was attributed to the fact that small valleys were filled by polymer chains $(0.1 \%$ in Scheme $1 \mathrm{a})$. With increased initiator density, more polymer chains were deposited on the surface after the same SIP time so that more valleys and peaks were buried under the polymer coatings (the $0.25 \%$ case in Figure 

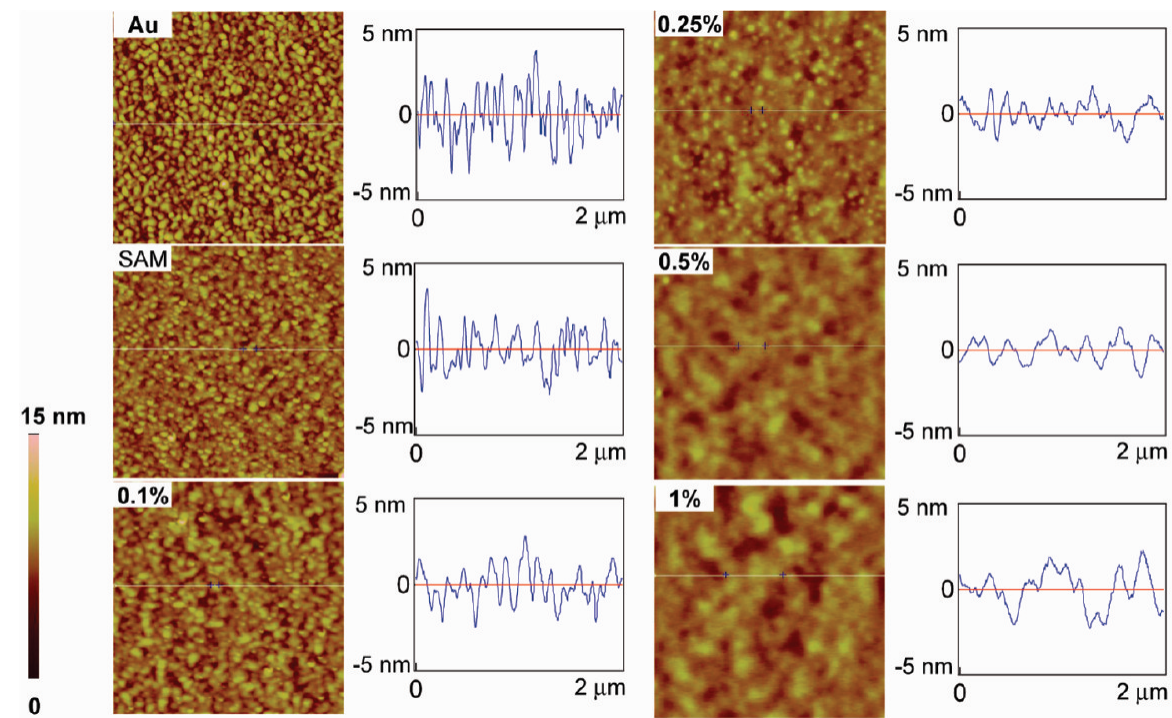

FIGURE 3. AFM height images and cross-sectional analysis of poly(OEGMA-co-HEMA) coatings grown from mixed SAMs with varied initiator densities $\left(\chi_{1}^{\text {Sol }}\right.$ from $0 \%$ to $\left.1 \%\right)$. The SIP time was $8 \mathrm{~h}$. All images have a scan size of $2 \times 2 \mu \mathrm{m}^{2}$. See Scheme $1 \mathrm{a}$, Figure 1 , and the text for detailed discussion.

Scheme 1. Proposed Mechanisms of Morphological Development of Polymer-Coated Gold Surface at the Air-Solid Interface as Functions of Initiator Density (a) and SIP Time (b) ${ }^{a}$

(a)

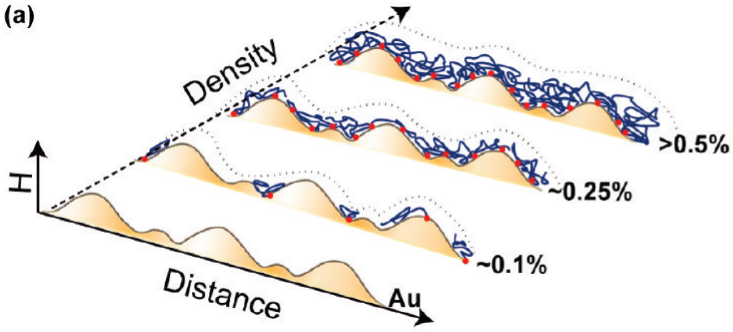

Note that height $(\mathrm{nm})$ and distance $(\mu \mathrm{m})$ were not drawn to scale.

3 and Scheme $1 \mathrm{a})$. In the case of $\chi_{1}^{\mathrm{Sol}}>0.5 \%$, the substrates were fully covered by polymer coating, resulting in a very smooth morphology.

We applied AFM to characterize the morphological evolution of polymer-coated Au surfaces at the air-solid interface as functions of SIP time, namely, after $0.5,1,2,4$, and $20 \mathrm{~h}$ of polymerization. For $\chi_{1}^{\text {Sol }}=0.5 \%$, the characterics of polymer coatings became dominant when the SIP time was larger than $4 \mathrm{~h}$ (Figure 4). The resulting polymer coating after $4 \mathrm{~h}$ of SIP was measured to be $10 \mathrm{~nm}$. For $\chi_{1}^{\text {Sol }}=5 \%$, the characterics of polymer coatings became dominant only after 10 min of SIP (Figure 5). The resulting polymer coating after $10 \mathrm{~min}$ of SIP was also $\sim 10 \mathrm{~nm}$. One could conclude here that a $10 \mathrm{~nm}$ coating was enough to bury the characteristics of gold surfaces. However, these two $10 \mathrm{~nm}$ coatings were very different. As we discussed above, both $0.5 \%$ and $5 \%$ were below the $10 \%$ threshold value of typical initiator efficiency so that one could assume each initiator would become a polymer chain, whose length (i.e., $M_{\mathrm{w}}$ ) was a function of polymerization time. Thus, we believed that although both have a $10 \mathrm{~nm}$ thickness, the $5 \%$ substrates had dense but short chains and the $0.5 \%$ substrates had fewer but longer chains. This is in agreement with a previous conclusion that for the same mass depostion, the combination of a short chain with high density is more effective in (b)

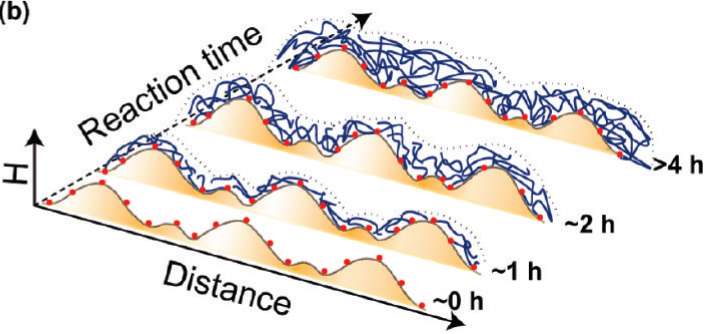

covering a surface than the combination of a longer chain with low density (45).

We further noticed that as the polymerization continued (SIP > $30 \mathrm{~min}$ ), the polymer chains gradually coalesced into large grains (Figure 5). Such a trend was not pronounced in the case of $\chi_{\mathrm{I}}^{\mathrm{Sol}}=0.5 \%$. Vancso et al. attributed those surface asperities to polymer chain aggregates resulting from crosslinking (51). Here, we believed it was due to chain entanglement. It implied that the matrix grown from substrates of high initiator density was not suitable for biosensor applications because the high density nature would block proteins from diffusing into the matrix. Those conclusions were applied below in the rational design of the biosensor matrix.

Rational Design and Optimization of Biosensor Matrix. A good functional matrix will greatly enhance the performance of a biosensor in that it can (i) increase the immobilization capacity of bait molecules, (ii) better preserve the biological activity of bait molecules, and (iii) lower the background (i.e., by reducing nonspecific protein adsorption). From the above studies, we identified that two major parameters of poly(OEGMA-co-HEMA) matrices could be controlled by SIP to produce an ideal surface for protein-based biosensors. These two parameters are shown in Scheme 2, namely, (1) $d_{1}$, the distance between 

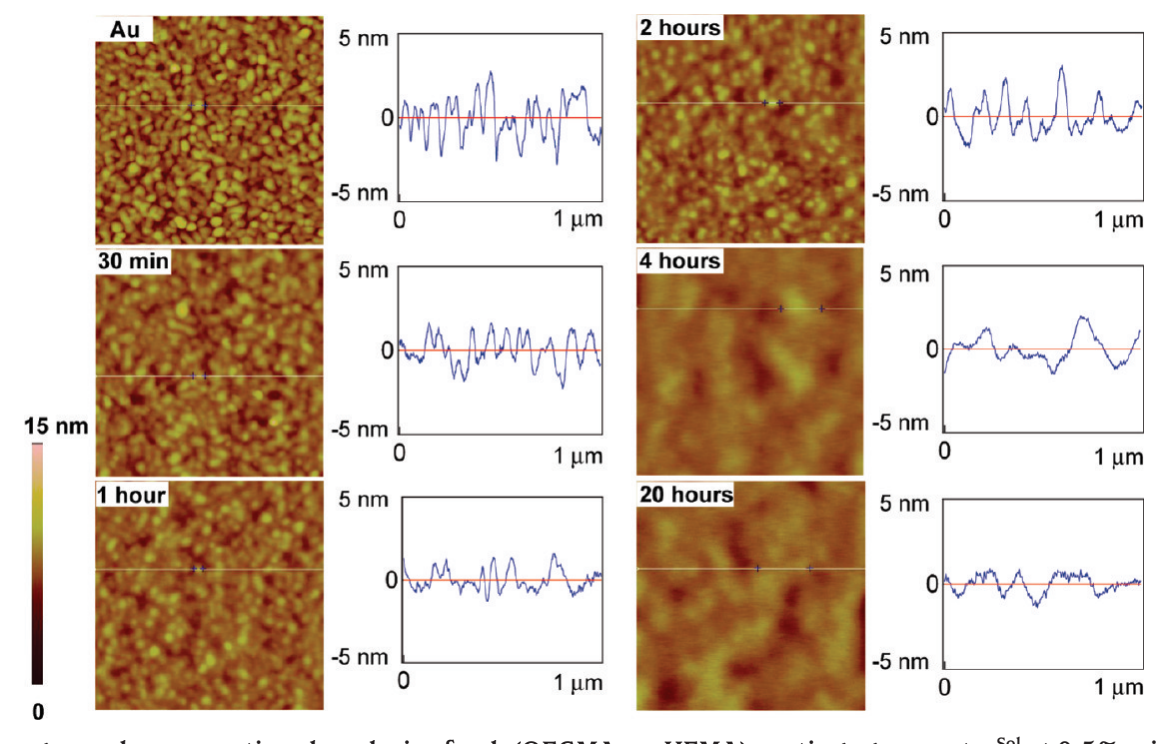

FIGURE 4. AFM height images and cross-sectional analysis of poly(OEGMA-co-HEMA) coatings grown at $\chi_{\mathrm{I}}^{\text {Sol }}$ at $0.5 \%$ with varied polymerization time. All images have a scan size of $1 \times 1 \mu \mathrm{m}^{2}$. See Scheme $1 \mathrm{~b}$, Figure $2 \mathrm{a}$, and the text for detailed discussion.
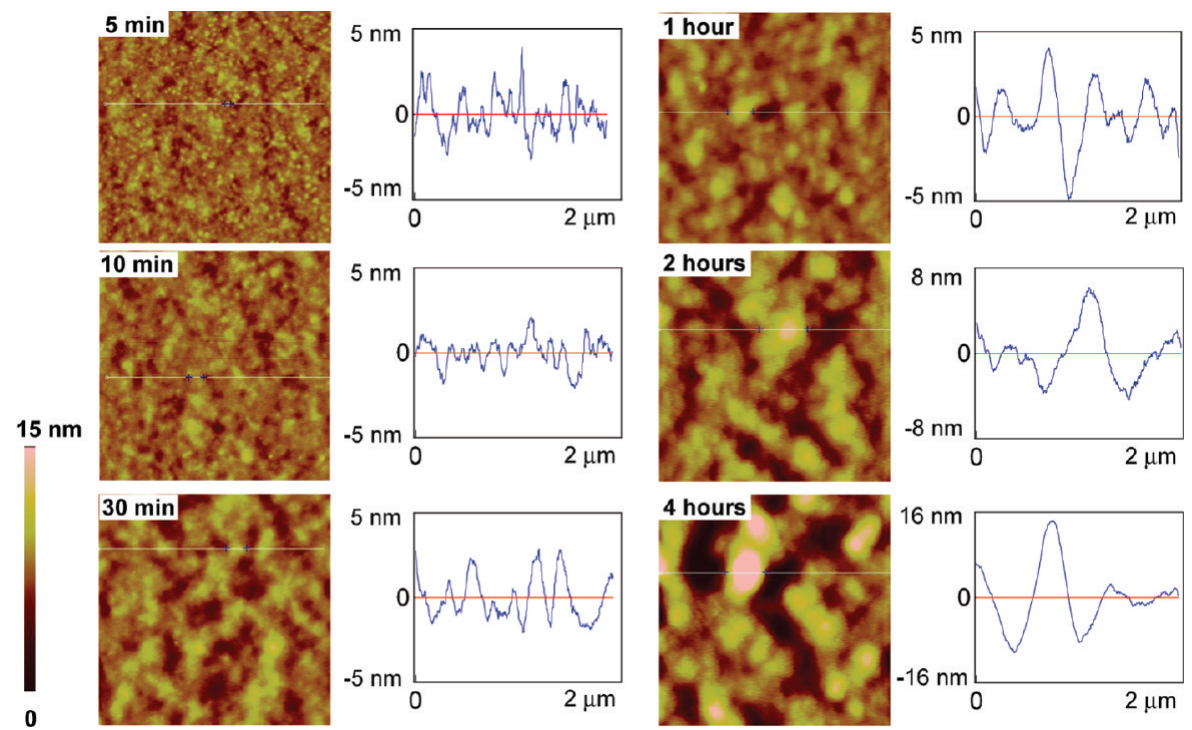

FIGURE 5. AFM height images and cross-sectional analysis of poly(OEGMA-co-HEMA) coatings grown at $\chi_{1}^{\text {sol }}$ at $5 \%$ with varied polymerization time. All images have a scan size of $2 \times 2 \mu \mathrm{m}^{2}$. See Scheme $1 \mathrm{~b}$, Figure $2 \mathrm{~b}$, and the text for detailed discussion.

Scheme 2. Nanoscale Separations $\left(d_{1}, d_{2}\right)$ Determine the Performance of the Polymer Matrix ${ }^{a}$

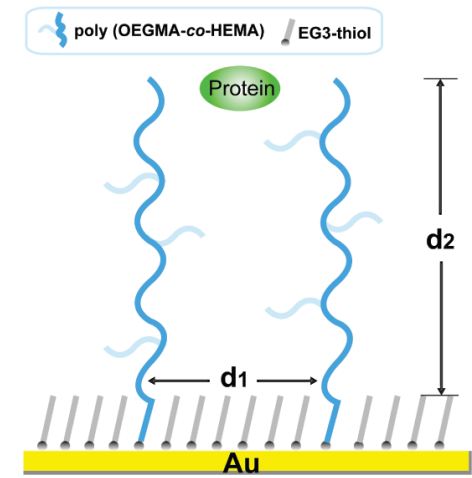

${ }^{a} d_{1}$ : Surface composition of mixed SAM of initiator and EG3-thiol. $d_{2}$ : SIP time.

two adjacent polymer chains, and (2) $d_{2}$, the thickness of the polymer matrices. SPR was first applied to optimize $d_{1}$ and $d_{2}$ so that a balance between nonfouling and immobilization capacity was achieved.

To determine the minimum initiator density that would generate a nonfouling matrix, we preparated poly(OEGMAco-HEMA) matrices with various $\chi_{1}^{\text {Sol }}$ values, namely, $0 \%$, $0.1 \%, 0.25 \%, 0.5 \%$, and $1.0 \%$, from one batch after $8 \mathrm{~h}$ of SIP. These matrices were used for SPR measurements (reported as resonance units, $\Delta R U$ ). Poly(ethylene glycol) (PEG) is well-known for its ability to reduce nonspecific protein adsorption (53). Many studies have tried to immobilize various forms of PEG onto substrates for producing a nonfouling surface, and density was identified as a key parameter for its nonfouling performance $(23,40,54-56)$. Nonspecific protein adsorption to the poly(OEGMA-coHEMA) matrices from different $\chi_{1}^{\text {Sol }}$ values was investigated by injecting rabbit IgG dissolved in a PBS buffer $\left(50 \mu \mathrm{g} \mathrm{mL}^{-1}\right)$. From Table 1, the EG3-thiol surface showed a high level of nonspecific protein adsorption. Since the EG3-thiol surface 
Table 1. Performances of Poly(OEGMA-co-HEMA) Matrices Grown from Various Densities Tested on $\mathrm{SPR}^{a}$

\begin{tabular}{|c|c|c|c|c|}
\hline$\chi_{1}^{\text {Sol }}$ & $\begin{array}{l}\text { nonspecific } \\
\text { protein } \\
\text { adsorption }\end{array}$ & NHSS/EDC & $\lg G$ & anti-IgG \\
\hline EG-SAM & $532 \pm 198$ & $1149 \pm 66$ & $1365 \pm 193$ & $2339 \pm 24$ \\
\hline $0.1 \%$ & $36 \pm 1$ & $1962 \pm 6$ & $2946 \pm 68$ & $2170 \pm 85$ \\
\hline $0.25 \%$ & $34 \pm 2$ & $3584 \pm 13$ & $3376 \pm 336$ & $2079 \pm 17$ \\
\hline $0.5 \%$ & $8 \pm 1$ & $6007 \pm 73$ & $6798 \pm 873$ & $1553 \pm 46$ \\
\hline $1.0 \%$ & $9 \pm 1$ & $13236 \pm 79$ & $2782 \pm 25$ & $1018 \pm 6$ \\
\hline $5.0 \%$ & 0 & $30436 \pm 223$ & $4045 \pm 9$ & $806 \pm 1$ \\
\hline
\end{tabular}

${ }^{a}$ See Scheme $1 \mathrm{a}$ and Figures 1 and 3 for details. The poly(OEGMA-co-HEMA) matrices were prepared from one batch after $8 \mathrm{~h}$ of SIP time. All reported values are $\Delta R U$

was reported to have superior nonfouling properties (55), we attributed this nonideal behavior to the defect of EG3SAM formed on a thermoevaporated Au film. In contrast, poly(OEGMA-co-HEMA) matrices grown from the same thermoevaporated Au films exhibited resistance to nonspecific protein adsorption. Such difference was due to the fact that these poly(OEGMA-co-HEMA) coatings were three-dimensional matrices and presented a higher surface density of OEG moieties than the EG-SAM. This explanation was supported by the observation that the nonspecific protein adsorption decreased from $36 \Delta$ RU to 0 (i.e., below the detection limit of SPR) when $\chi_{1}^{\text {Sol }}$ increased from $0.1 \%$ to $5 \%$. Such observation agreed with our aforementioned AFM study that poly(OEGMA-co-HEMA) at $\chi_{\mathrm{I}}^{\text {Sol }}=0.5 \%$ showed a complete coverage of the Au surface. For biosensor matrices, the immobilization capacity is as important as the nonfouling property. Now, we turn to optimizing the immobilization capacity of poly(OEGMA- co-HEMA) matrices.

The immobilization capacities for carboxylated poly(OEGMA-co-HEMA) matrices were evaluated by two indices, namely, the number of carboxyl groups ready to be activated (the NHSS/EDC column in Table 1) and the number of proteins immobilized (the IgG column in Table 1). The number of carboxyl groups increased monotonically with the increase of $\chi_{1}^{\text {Sol }}$. However, the number of immobilized IgG's reached a peak value at $\chi_{1}^{\text {sol }}=0.5 \%$. The decline of immobilization capacity was due to the increased polymer chain density, which made the diffusion more difficult. Thus, to achieve a balanced nonfouling property and immobilization capacity, poly(OEGMA-co-HEMA) at $0.1 \%<\chi_{I}^{\text {Sol }}<0.5 \%$ was preferred (i.e., the optimized $d_{1}$ in Scheme 2 ).

Since most biosensor applications require multiple recognition steps such as antigen-antibody recognition after antigen immobilization, we applied rabbit IgG and goat antirabbit IgG as model proteins to further optimize the poly(OEGMA-co-HEMA) matrices. From the anti-IgG column in Table 1, we found that the recognition capacity decreaesd

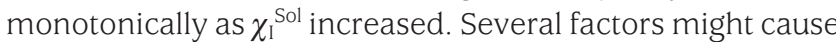
this phenomenon: (i) With the increased $\chi_{1}^{\text {Sol }}$ value, the diffusion of anti-IgG into and out of the matix became more difficult. (ii) A large number of activation sites in the matrix could result in multiple attachment points between proteins
Table 2. Performance Tests of Poly(OEGMA-co-HEMA) Matrices with Different Thicknesses Measured by SPR ${ }^{a}$

\begin{tabular}{|c|c|c|c|c|c|}
\hline $\begin{array}{l}\text { SIP } \\
\text { time }\end{array}$ & $\begin{array}{l}\text { thickness } \\
\text { (nm) }\end{array}$ & $\begin{array}{l}\text { nonspecific } \\
\text { protein } \\
\text { adsorption }\end{array}$ & $\begin{array}{l}\text { NHSS/ } \\
\text { EDC }\end{array}$ & $\operatorname{Ig} G$ & anti-IgG \\
\hline $10 \mathrm{~min}$ & 1.1 & $55 \pm 7$ & $1124 \pm 8$ & $2122 \pm 8$ & $1956 \pm 96$ \\
\hline $30 \mathrm{~min}$ & 2.6 & $73 \pm 9$ & $1291 \pm 517$ & $2264 \pm 512$ & $2470 \pm 124$ \\
\hline $1 \mathrm{~h}$ & 3.0 & $45 \pm 7$ & $1492 \pm 140$ & $3246 \pm 678$ & $2580 \pm 76$ \\
\hline $2 \mathrm{~h}$ & 3.4 & $58 \pm 13$ & $1364 \pm 226$ & $2648 \pm 51$ & $2622 \pm 76$ \\
\hline $4 \mathrm{~h}$ & 9.7 & $27 \pm 1$ & $2445 \pm 12$ & $3659 \pm 465$ & $2504 \pm 92$ \\
\hline $8 \mathrm{~h}$ & 17.2 & $8 \pm 1$ & $6007 \pm 73$ & $6798 \pm 874$ & $1553 \pm 46$ \\
\hline $20 \mathrm{~h}$ & 20.4 & $6 \pm 1$ & $7450 \pm 102$ & $4578 \pm 378$ & $1946 \pm 253$ \\
\hline
\end{tabular}

${ }^{a}$ See Scheme $1 \mathrm{~b}$ and Figures $2 \mathrm{a}$ and 4 for details. All poly(OEGMA-co-HEMA) matrices were prepared at $\chi_{1}^{\mathrm{Sol}}=0.5 \%$.

and the matrix, which might cause proteins to lose their bioactivity. (iii) The presence of multiple attachment points between proteins and the matrix may cause cross-linking, which would prevent anti-IgG to diffuse into the matrix. Thus, taken together, we idenfitied $\chi_{1}^{\mathrm{Sol}}=0.5 \%$ as the optimal condition for biosensor applications.

Now, we turn to optimize the thickness $\left(d_{2}\right.$ in Scheme 2) of poly(OEGMA-co-HEMA) matrices. It is clear from Table 2 that the increase in thickness was effective in reducing nonspecific protein adsorption. A $\sim 17 \mathrm{~nm}$ poly(OEGMA-coHEMA) coating was prepared after $8 \mathrm{~h}$ of SIP at $\chi_{\mathrm{I}}^{\text {Sol }}=0.5 \%$, which effectively reduced nonspecific protein adsorption to a negligible level. Similar to the above case, the number of carboxyl groups increased monotonically as the thickness increased, but the immobilization and recognition capapcities showed peak values at $8 \mathrm{~h}$ (i.e., $\sim 17 \mathrm{~nm}$ ) and $2 \mathrm{~h}$ (i.e., $\sim 3.4 \mathrm{~nm}$ ) of SIP time, respecitively. To summarize, we have identified the conditions for optimized poly(OEGMA-coHEMA) matrices: $8 \mathrm{~h}$ of SIP from substrates at $\chi_{\mathrm{I}}{ }^{\text {Sol }}=0.5 \%$ and a ratio of monomers of $1: 1$. Now, we will use such a matrix for various applications.

Applications. QCM and SPR are two typical solidphase-based technologies for biomolecular interaction studies. We tested the poly(OEGMA-co-HEMA) matrices on both QCM and SPR, using rabbit IgG and goat anti-rabbit IgG as the model bait-prey pair. For a $\mathrm{COOH}$ functionalized QCM chip, it was first probed with HAc $(2 \mathrm{mM}, \mathrm{pH}=4.6)$ as the running buffer, followed by NE activation. Then, rabbit IgG (50 $\mu \mathrm{g} \mathrm{mL} \mathrm{mL}^{-1}$ ) was introduced, resulting in $289.5 \mathrm{~Hz} \mathrm{a}$ decrease in frequency. Ethanol amine (EtAmine at $1 \mathrm{M}, \mathrm{pH}$ $=8.5$ ) was applied to deactivate the remaining active carboxyl groups. The running buffer was then switched to PBS ( $\mathrm{pH}=7.4$ ), followed by flowing it through goat antirabbit IgG $\left(50 \mu \mathrm{g} \mathrm{mL}^{-1}\right)$. After switching back to PBS, there was a $254.8 \mathrm{~Hz}$ frequency decrease due to bait-prey recognition. For a control experiment, we carried out the same the procedure as given in Figure $6 \mathrm{a}$ without immobilization of the rabbit IgG. It was evident that the poly(OEGMA-co-HEMA) exhibited a remarkable nonfouling property: the nonspecific adsorption was below the detection limit of QCM.

SPR has become a standard technology for measuring kinetics of bimolecular interactions. In the present study, we 

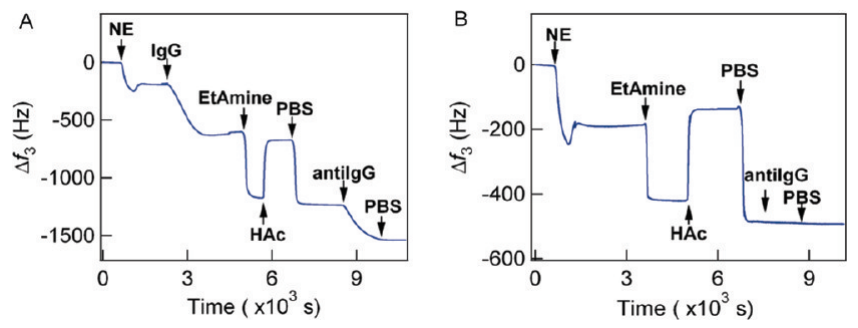

FIGURE 6. QCM biosensor-based poly(OEGMA-co-HEMA) matrix studies of rabbit IgG and goat anti-rabbit IgG recognition. (A) A typical run of rabbit IgG and goat anti-rabbit IgG recognition study on QCM. (B) nonspecific adsorption was evaluated by the introduction of goat anti-rabbit IgG to the surface without IgG immobilization.
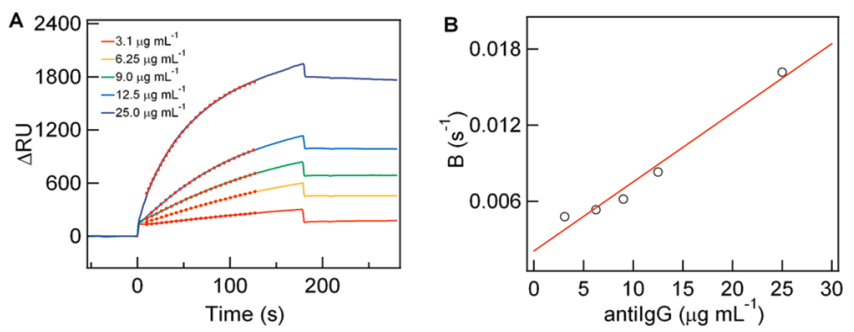

FIGURE 7. Curve fitting for affinity and kinetic constant determination by SPR. (A) The binding curves were reconstructed for clarity and fitted according to eqs 3 and 4 . (B) The fitted values were linearly fitted, resulting in $k_{\mathrm{a}}=3.0 \times 10^{-4} \mu \mathrm{g}^{-1} \mathrm{~mL} \mathrm{~s}^{-1}, k_{\mathrm{d}}=1.4 \times 10^{-3} \mathrm{~s}^{-1}$, and $K_{\mathrm{A}}=3.4 \times 10^{7} \mathrm{M}^{-1}$.

applied the poly(OEGMA-co-HEMA) matrices to carry out a systematic study of the affinity and kinetic rate constants for IgG/anti-IgG (see the Experimental Section for details). Here, we applied eqs 3 and 4 to obtain affinity and kinetic rate constants (57).

$$
\begin{gathered}
\Delta \mathrm{RU}=\frac{k_{\mathrm{a}} C \Delta \mathrm{RU}_{\max }}{\left(k_{\mathrm{a}} C+k_{\mathrm{d}}\right)}\left(1-\exp \left[-\left(k_{\mathrm{a}} C+k_{\mathrm{d}}\right) t\right]\right) \\
B=k_{\mathrm{a}} \times C+k_{\mathrm{d}}
\end{gathered}
$$

This matrix was also compared with commercially available dextran matrix (CM5 from BIAcore) for SecBEc and SecABE interactions, and they gave similar results for the value of $K_{\mathrm{D}}$ of $2.0 \times 10^{-6} \mathrm{M}$ and $2.3 \times 10^{-6} \mathrm{M}$ for poly-
(OEGMA-CO-HEMA) and CM5, respectively. Curve fittings for affinity and kinetic constant determination by SPR are shown in Figure 7.

The poly(OEGMA-co-HEMA) matrix was further tested as a solid supporting material for protein microarrays. Fluorescently labeled BSA solutions from 10 to $100 \mu \mathrm{g} \mathrm{mL} \mathrm{m}^{-1}$ were printed on the carboxylated poly(OEGMA-co-HEMA) matrix surface. The printed arrays were kept in at $70 \%$ humidity for $2 \mathrm{~h}$ under room temperature and then washed with PBST and PBS to remove the unreacted proteins. Finally, a laser confocal scanner (LuxScanTM-10K/B) was used to confirm the attachment of fluorescently labeled BSA to the poly(OEGMA-co-HEMA) matrix. The signal intensity of fluorescently labeled BSA was linearly dependent on the concentration of the BSA, and no saturation was observed up to 100 $\mu \mathrm{g} \mathrm{mL}^{-1}$, indicating that the poly(OEGMA-co-HEMA) matrix has high binding capacity for microarray applications (Figure $8 a, b)$. We further tested whether the immobilized rabbit IgG could be used to specifically capture anti-IgG. After IgG immobilization, fluorescently labeled goat anti-rabbit IgG was added and incubated for $2 \mathrm{~h}$ under room temperature. A high signal-to-background ratio was found for a concentration of goat anti-Rabbit IgG of $10 \mathrm{ng} \mathrm{\textrm {mL } ^ { - 1 }}$ (Figure 8c), indicating that the immobilized IgG in the matrix retains its biological activity and could recognize the prey proteins for microarray applications.

\section{CONCLUSION}

SIP has proven to be a facile method for producing dense polymer brushes on various surfaces (44). However, very few reports have paid attention to the SIP from substrates of low initiator density. We demonstrated here that SIP from substrates of low initiator density enabled us to carefully adjust nanoscale separations $\left(d_{1}, d_{2}\right)$ of a biosensor matrix so that ideal surface chemistry could be achieved. This work made contributions to this field in the following ways: (i) This reported method is general for the preparation of ideal surface chemistries for biosensors of many varieties. As the dimensions of biosensors go down and structural complexity goes up, a general yet robust method for surface modification will help scientists to concentrate on core issues. We expect that our reported strategy will promote the develop-

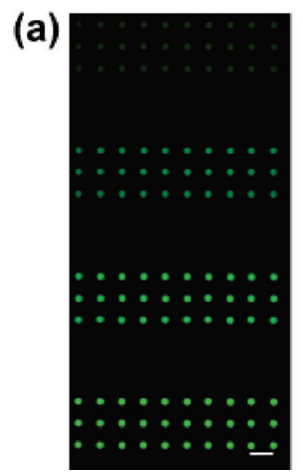

(b)

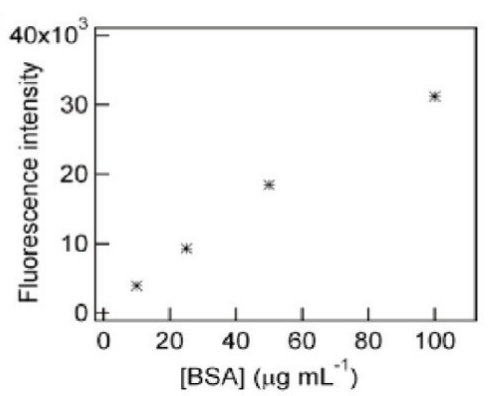

(c)

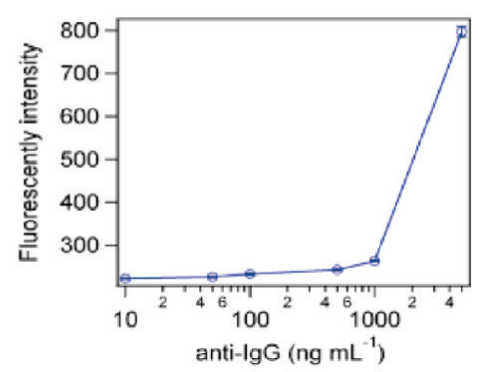

FIGURE 8. Poly(OEGMA-co-HEMA) matrix tested as a solid supporting material for microarrays. (a) The fluorescent image of a fluorescently labeled BSA microarray. The scale bar in the image is $400 \mu \mathrm{m}$. (b) The signal intensity of fluorescently labeled BSA. The series concentrations of fluorescently labeled BSA were $10,25,50$, and $100 \mu \mathrm{g} \mathrm{mL}^{-1}$. No saturation was observed up to $100 \mu \mathrm{g} \mathrm{mL}^{-1}$. (c) Dose-response curves for anti-IgG and IgG recognition. The immobilization concentration of IgG was $100 \mu \mathrm{g} \mathrm{mL}^{-1}$. 
ment of new biosensors. (ii) This study delivered an important message that size/distance matters. A balanced nonfouling and immobilization capacity was only achieved at a very low initiator density (eg: $\chi_{\mathrm{I}}^{\mathrm{Sol}}=0.5 \%$ ). It is expected that substrates with different shapes and geometries, such as nanoparticles, beads, and hollow spheres, will require individual optimization processes. Given the difficulties in characterizing surfaces after SIP from substrates of low initiator densities, one could take the reported $d_{1}$ value as a good reference value. This report shall encourage researchers to explore new frontiers in SIP that go beyond polymer brushes.

Acknowledgment. This project was supported by the 100 Talents Program of the Chinese Academy of Sciences (08BM031001), the Special Foundation of the President of the Chinese Academy of Sciences, NSFC (20604002) to H.M., the National High Technology Research and Development Program of China (2009AA04Z125), and the National Basic Research Program of China (2009CB320300). Messrs. W. J. Zhang and X. M. Ma are greatly acknowledged for their technical support. We thank the Public Center for Characterization and Test at SINANO.

\section{REFERENCES AND NOTES}

(1) Tsujii, Y.; Ohno, K.; Yamamoto, S.; Goto, A.; Fukuda, T. Adv. Polym. Sci. 2006, 1-45.

(2) Bain, C. D.; Troughton, E. B.; Tao, Y. T.; Evall, J.; Whitesides, G. M.; Nuzzo, R. G. J. Am. Chem. Soc. 1989, 111, 321-335.

(3) Ulman, A. Chem. Rev. 1996, 96, 1533-1554.

(4) Tugulu, S.; Arnold, A.; Sielaff, I.; Johnsson, K.; Klok, H. A. Biomacromolecules 2005, 6, 1602-1607.

(5) Perruchot, C.; Khan, M. A.; Kamitsi, A.; Armes, S. P.; von Werne, T.; Patten, T. E. Langmuir 2001, 17, 4479-4481.

(6) Miller, M. D.; Baker, G. L.; Bruening, M. L. J. Chromatogr. A 2004, 1044, 323-330

(7) Matrab, T.; Chehimi, M. M.; Boudou, J. P.; Benedic, F.; Wang, J.; Naguib, N. N.; Carlisle, J. A. Diamond Relat. Mater. 2005, 15, $639-$ 644.

(8) Xu, F. J.; Li, J.; Su, F.; Zhao, X. S.; Kang, E. T.; Neoh, K. G. J. Nanosci. Nanotechnol. 2008, 8, 5858-5863.

(9) Liu, P. Mater. Res. Innovations 2005, 9, 103-105.

(10) Xu, F. J.; Zhao, J. P.; Kang, E. T.; Neoh, K. G.; Li, J. Langmuir 2007 23, 8585-8592.

(11) Miller, P. J.; Matyjaszewski, K. Macromolecules 1999, 32, 8760 8767.

(12) Wu, Y. Z.; Huang, Y. Y.; Ma, H. W. J. Am. Chem. Soc. 2007, 129, 7226.

(13) Sitti, M.; Cusick, B.; Aksak, B.; Nese, A.; Lee, H. I.; Dong, H. C.; Kowalewski, T.; Matyjaszewski, K. ACS Appl. Mat. Interfaces 2009 1, 2277-2287.

(14) Kim, J. B.; Bruening, M. L.; Baker, G. L. J. Am. Chem. Soc. 2000, 122, 7616-7617

(15) Matrab, T.; Chehimi, M. M.; Perruchot, C.; Adenier, A.; Guillez, A.; Save, M.; Charleux, B.; Cabet-Deliry, E.; Pinson, J. Langmuir 2005, 21, 4686-4694.

(16) Zhang, F.; Kang, E. T.; Neoh, K. G.; Wang, P.; Tan, K. L. Biomaterials 2001, 22, 1541-1548.

(17) Chen, R. X.; Zhu, S. P.; Maclaughlin, S. Langmuir 2008, 24, $6889-$ 6896.

(18) Li, X. L.; Wang, X. R.; Zhang, L.; Lee, S. W.; Dai, H. J. Science 2008, $319,1229-1232$

(19) Liu, P.; Wang, T. M.; Su, Z. X. J. Nanosci. Nanotechnol. 2006, 6, $1684-1688$.

(20) Bontempo, D.; Heredia, K. L.; Fish, B. A.; Maynard, H. D. J. Am Chem. Soc. 2004, 126, 15372-15373.
(21) Bontempo, D.; Maynard, H. D. J. Am. Chem. Soc. 2005, 127, 6508 6509.

(22) Heredia, K. L.; Bontempo, D.; Ly, T.; Byers, J. T.; Halstenberg, S.; Maynard, H. D. J. Am. Chem. Soc. 2005, 127, 16955-16960.

(23) Ma, H. W.; Hyun, J. H.; Stiller, P.; Chilkoti, A. Adv. Mater. 2004, $16,338$.

(24) Ma, H. W.; Li, D. J.; Sheng, X.; Zhao, B.; Chilkoti, A. Langmuir 2006, 22, 3751-3756.

(25) Zhang, Z.; Chao, T.; Chen, S. F.; Jiang, S. Y. Langmuir 2006, 22, 10072-10077.

(26) Statz, A. R.; Barron, A. E.; Messersmith, P. B. Soft Matter 2008, 4, 131-139.

(27) Dalsin, J. L.; Hu, B. H.; Lee, B. P.; Messersmith, P. B. J. Am. Chem. Soc. 2003, 125, 4253-4258.

(28) Azzaroni, O.; Brown, A. A.; Huck, W. T. S. Adv. Mater. 2007, 19, $151-154$

(29) Sun, T. L.; Song, W. L.; Jiang, L. Chem. Commun. 2005, $1723-$ 1725.

(30) Feng, X. J.; Jiang, L. Adv. Mater. 2006, 18, 3063-3078.

(31) Sun, T. L.; Wang, G. J.; Feng, L.; Liu, B. Q.; Ma, Y. M.; Jiang, L.; Zhu, D. B. Angew. Chem., Int. Ed. 2004, 43, 357-360.

(32) Dai, S.; Ravi, P.; Tam, K. C. Soft Matter 2008, 4, 435-449.

(33) Ayres, N.; Boyes, S. G.; Brittain, W. J. Langmuir 2007, 23, 182189.

(34) Huck, W. T. S. Mater. Today 2008, 11, 24-32.

(35) Kaholek, M.; Lee, W. K.; Ahn, S. J.; Ma, H. W.; Caster, K. C.; LaMattina, B.; Zauscher, S. Chem. Mater. 2004, 16, 3688-3696.

(36) Jeon, N. L.; Choi, I. S.; Whitesides, G. M.; Kim, N. Y.; Laibinis, P. E.; Harada, Y.; Finnie, K. R.; Girolami, G. S.; Nuzzo, R. G. Appl. Phys. Lett. 1999, 75, 4201-4203.

(37) Shah, R. R.; Merreceyes, D.; Husemann, M.; Rees, I.; Abbott, N. L.; Hawker, C. J.; Hedrick, J. L. Macromolecules 2000, 33, 597-605.

(38) Gao, W. P.; Liu, W. G.; Mackay, J. A.; Zalutsky, M. R.; Toone, E. J.; Chilkoti, A. Proc. Natl. Acad. Sci.U. S. A. 2009, 106, 15231-15236.

(39) Qian, T. C.; Li, Y. F.; Wu, Y. Z.; Zheng, B.; Ma, H. W. Macromolecules 2008, 41, 6641-6645.

(40) Larsson, A.; Ekblad, T.; Andersson, O.; Liedberg, B. Biomacromolecules 2007, 8, 287-295.

(41) Cullen, S. P.; Liu, X.; Mandel, I. C.; Himpsel, F. J.; Gopalan, P. Langmuir 2008, 24, 913-920.

(42) Ma, H. W.; Wu, Y. Z.; Yang, X. L.; Liu, X.; He, J. A.; Fu, L.; Wang, J.; Xu, H. K.; Shi, Y.; Zhong, R. Q. Anal. Chem. 2010, 82, $6338-$ 6342 .

(43) Hucknall, A.; Rangarajan, S.; Chilkoti, A. Adv. Mater. 2009, 21, $2441-2446$.

(44) Barbey, R.; Lavanant, L.; Paripovic, D.; Schuwer, N.; Sugnaux, C.; Tugulu, S.; Klok, H. A. Chem. Rev. 2009, 109, 5437-5527.

(45) Oligo(ethylene glycol) Based Nonfouling Surfaces-Engineering Flat Surfaces and Microstructures for Biosensors, Tissue Engineering and Biomedical Applications; Ma, H., Ed.; VDM Verlag Dr. Muller Aktiengesellschaft \& Co. KG: Germany, 2009.

(46) Feng, W.; Zhu, S. P.; Ishihara, K.; Brash, J. L. Biointerphases 2006, $1,50-60$

(47) Kizhakkedathu, J. N.; Brooks, D. E. Macromolecules 2003, 36, $591-598$

(48) Nagase, K.; Kobayashi, J.; Kikuchi, A. I.; Akiyama, Y.; Kanazawa, H.; Okano, T. Langmuir 2008, 24, 511-517.

(49) Jones, D. M.; Brown, A. A.; Huck, W. T. S. Langmuir 2002, 18, 1265-1269.

(50) Liu, H.; Li, M.; Lu, Z. Y.; Zhang, Z. G.; Sun, C. C. Macromolecules 2009, 42, 2863-2872

(51) Benetti, E. M.; Reimhult, E.; de Bruin, J.; Zapotoczny, S.; Textor, M.; Vancso, G. J. Macromolecules 2009, 42, 1640-1647.

(52) Ma, H. W.; Wells, M.; Beebe, T. P.; Chilkoti, A. Adv. Funct. Mater. 2006, 16, 640-648.

(53) Zalipsky, S. Bioconjugate Chem. 1995, 6, 150-165.

(54) Wang, P.; Tan, K. L.; Kang, E. T.; Neoh, K. G. J. Mater. Chem. 2001, $11,2951-2957$.

(55) Riepl, M.; Enander, K.; Liedberg, B.; Schaferling, M.; Kruschina, M.; Ortigao, F. Langmuir 2002, 18, 7016-7023.

(56) Lee, S.; Spencer, N. D. Langmuir 2008, 24, 9479-9488.

(57) Karlsson, R.; Falt, A. J. Immunol. Methods 1997, 200, 121-133.

AM1 006832 